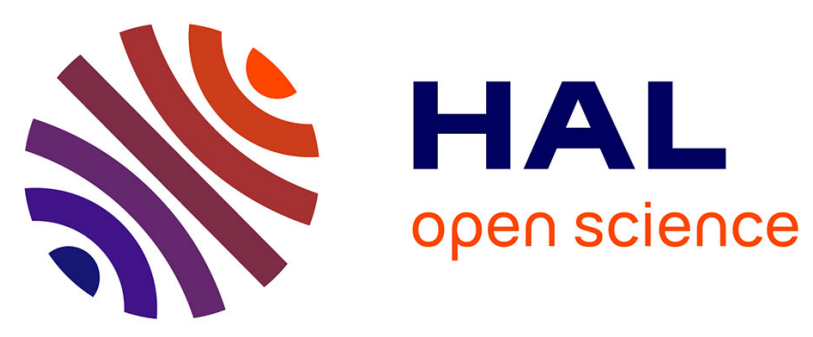

\title{
Generation of stable Xenopus laevis transgenic lines expressing a transgene controlled by weak promoters.
}

Anne L'Hostis-Guidet, Gaëlle Recher, Brigitte Guillet, Abdulrahim Al-Mohammad, Pascal Coumailleau, François Tiaho, Daniel Boujard, Thierry Madigou

\section{To cite this version:}

Anne L'Hostis-Guidet, Gaëlle Recher, Brigitte Guillet, Abdulrahim Al-Mohammad, Pascal Coumailleau, et al.. Generation of stable Xenopus laevis transgenic lines expressing a transgene controlled by weak promoters.. Transgenic Research, 2009, 18 (5), pp.815-27. 10.1007/s11248-009-9273-0 . hal-00416493

\section{HAL Id: hal-00416493 \\ https://hal.science/hal-00416493}

Submitted on 14 Sep 2009

HAL is a multi-disciplinary open access archive for the deposit and dissemination of scientific research documents, whether they are published or not. The documents may come from teaching and research institutions in France or abroad, or from public or private research centers.
L'archive ouverte pluridisciplinaire HAL, est destinée au dépôt et à la diffusion de documents scientifiques de niveau recherche, publiés ou non, émanant des établissements d'enseignement et de recherche français ou étrangers, des laboratoires publics ou privés. 
Generation of stable Xenopus laevis transgenic lines expressing a transgene controlled by weak promoters

Anne L'HOSTIS-GUIDET ${ }^{1}$, Gaëlle RECHER ${ }^{1}$, Brigitte GUILLET ${ }^{2}$, Abdulrahim ALMOHAMMAD $^{2}$, Pascal COUMAILLEAU $^{1}$, François TIAHO $^{1}$, Daniel BOUJARD ${ }^{1,2}$, Thierry MADIGOU $^{1,2 *}$

${ }^{1}$ Equipe SCANING, Interactions cellulaires et moléculaires

${ }^{2}$ Centre de Ressources Biologiques « Xénope »

UMR 6026 CNRS, Université de Rennes 1, 35042 Rennes, France

*E-mail: thierry.madigou@ univ-rennes1.fr,

Telephone: +332232368 89, Fax: +33223235052. 


\begin{abstract}
Combining two existing protocols of trangenesis, namely the REMI and the I-SceI meganuclease methods, we generated Xenopus leavis expressing a transgene under the control of a promoter that presented a restricted pattern of activity and a low level of expression. This was realized by coincubating sperm nuclei, the I-SceI enzyme and the transgene prior to transplantation into unfertilized eggs. The addition of the woodchuck hepatitis virus posttranscriptional regulatory element (WPRE) in our constructs further enhanced the expression of the transgene without affecting the tissue-specificity of the promoter activity. Using this combination of methods we produced high rates of fully transgenic animals that stably transmitted the transgene to the next generations with a transmission rate of $50 \%$ indicating a single integration event.
\end{abstract}

Keywords: Xenopus laevis; transgenesis; I-SceI Meganuclease; Posttranscriptional regulatory element (WPRE) 


\section{Introduction}

The amphibian Xenopus laevis has played a key role in the study of vertebrate development and the establishment of important concepts in developmental biology (for review see Stern 2005; Heasman 2006). The large size of eggs and embryos permit microsurgical manipulation. It is also possible to over-express specific gene products in particular regions of the embryo by micro-injection of synthetic mRNA or to inhibit zygotic gene function by the use of dominant negative approach (Amaya et al. 1991) or antisense morpholinos (Heasman et al. 2000).

The ability to generate transgenic Xenopus has reinforced the interest in this model. This was first achieved in the late 90's when Kroll and Amaya (1996) described a method based on the Restriction Enzyme Mediated Integration (REMI) developed in Dictyostelium discoideum (Kuspa and Loomis 1992). According to these authors, the transgene was supposed to integrate in the chromatindecondensed sperm nuclei before transplantation in unfertilized eggs. This method was further simplified by omitting egg extracts and restriction enzyme to avoid the weakening of decondensed sperm nuclei (Sparrow et al. 2000). It enables the production of non mosaic and stable transgenic animals. However, one of the major drawbacks is that chromosomal integration occurs as concatemers ( 2 to 6 copies) at 4-8 sites of the genome.

In 2002, a new approach based on the use of a yeast transposase, the meganuclease I-SceI, was proposed to generate transgenic fishes (Thermes et al. 2002). The co-injection in the cytoplasm of one-cell stage embryos of the enzyme and a plasmid carrying the transgene flanked by two restriction sites for I-SceI allowed the rapid integration of a functional insert. Moreover, in the fish species, the observed germline transmission rates were about $50 \%$ suggesting a single integration of the transgene into one-cell stage embryos. This was confirmed by Southern blot analysis since the reporter was found integrated as a single copy or few copies in tandem into mostly single sites within the genome (Thermes et al. 2002).

This transgenesis method using meganuclease has been successfully used in other fish species 
(zebrafish Danio rerio: Grabher et al. 2004) and the ascidian Ciona savignyi (Deschet et al. 2003). More recently, it has been adapted to different amphibian species such as axolotl (Sobkow et al. 2006) or the anurans Xenopus laevis (Pan et al. 2006) and Xenopus tropicalis (Ogino et al. 2006). Contrary to what happens in fishes, transgenic amphibians produced with this method were mainly mosaic and only 10 to $15 \%$ of developing embryos showed a non-mosaic expression of the transgene. The majority of the F0 founders transmitted the transgene to less than $50 \%$ of their progeny. Interestingly, the main advantage of this method, namely the few transgene copy number, was preserved in Xenopus.

Other methods, based on the use of different transposases, were also proposed. However, these protocols need the co-injection of the plasmid carrying the transgene and the mRNA encoding the transposase. The delay between the injection of mRNA and the production in the cells of the active enzyme led to the production of mosaic animals that were of limited use for promoter analysis in the F0 founder generation (Allen and Weeks 2005; Hamlet et al. 2006; Sinzelle et al. 2006).

From all these studies, it seems quite difficult to obtain stable F1 generation which will be useful for the amphibian community. Moreover, all the experiments conducted so far have been realised with a little number of promoters in combination with GFP. Despite the obvious advantage of GFP to monitor expression, the threshold level required for detection makes it inappropriate to assess low level of gene expression.

Using a combination of REMI and I-SceI meganuclease methods we produced high rates of fully transgenic Xenopus bearing a few number of transgene copies. We used the promoter of the pan neural gene neuro- $\beta$ tubulin (N $\beta$ Tub) which has been previously used (Ryffel and Lingott 2000) and the promoter of the bHLH neurogenic differentiation factor NeuroD encoding gene which has a low and restricted transcriptional activity (Lee et al. 1995). However, this method was not sufficient to obtain convincing expression of GFP under the control of the neuroD promoter. This could be achieved either by boosting transcription or by acting on post-transcriptional events, which would limit the potential alteration of the promoter tissue-specificity. The ability of a post-transcriptional 
regulatory element from woodchuck hepatitis virus (WPRE) to enhance the expression of a transgene in retrovirus (Zufferey et al. 1999) or adenovirus (Glover et al. 2002; Xu et al. 2003) vectors without affecting the tissue specificity (Glover et al. 2002) has already been demonstrated. However, to date, the efficiency of cis-acting elements such as WPRE has only been assessed in mammals or mammalian cell lines and little is known about its ability to enhance the in vivo expression of a transgene in a non-mammalian species. Thus, in this work, we also performed transgenesis in Xenopus laevis with constructs containing the neuroD promoter, which drives the expression of the enhanced green fluorescent protein (EGFP) and the WPRE element, localized in the 3'UTR of the EGFP sequence. 


\section{Methods}

\section{Plasmid constructs}

The pEGFP-1 reporter vector (Clontech) was modified by introducing double-strand oligonucleotides containing an I-SceI recognition site (Colleaux et al. 1988; Thermes et al. 2002) in the $B g l$ II and $A f l$ II restriction sites to generate pSce-EGFP-Sce. For transgenesis, a 3.8 kb neuroBtubulin promoter from Xenopus (accession number: EF989124) was inserted in the Hind III site of pSce-EGFP-Sce to generate pSce-NBT-EGFP-Sce. A $1.3 \mathrm{~kb}$ neuroD promoter fragment (accession number: EF591766) was cloned from genomic libraries generated using the Universal Genome Walker kit (Clontech) according to the manufacturer's protocol. Two reporter plasmids were then constructed, containing either the entire cloned 5' flanking region (1.3neuroD) or only the $320 \mathrm{bp}$ proximal region $(0.3$ neuroD) in the Sac I / Hind III sites of pGL3 reporter plasmid (Promega) to perform transfection assays. These constructs were then designated as p0.3neuroD-Luc and p1.3neuroD-Luc. An expression vector, pCS-MT-xNGNR-1a, (provided by Dr. D.J. Anderson, Howard Hughes Medical Institute, California Institute of Technology, Pasadena, California) was used in co-transfection assays to check the ability of the xneuroD promoter fragments to be induced. The two fragments of xneuroD promoter were also introduced into the Xho I / Bam HI (O.3neuroD) or Sma I (1.3neuroD) restriction sites of pSce-EGFP-Sce for transgenesis. A WPRE element (Woodchuck Post-transcriptional Regulatory Element, provided by $\operatorname{Pr}$ D. Trono, Geneva, Switzerland; accession number: J04514) was inserted in the Xba I site of pGL3, p0.3neuroD-Luc and p1.3neuroD-Luc used in transfection studies or the Not I site of p0.3neuroD-EGFP and p1.3neuroD-EGFP used in transgenesis, between the reporter gene and the polyadenylation signal.

\section{Culture of $P 19$ cells and transfection assays}

P19 mouse multipotent embryonic carcinoma cells were grown in DMEM (Dulbecco's Modified Eagle Medium, Invitrogen Gibco BRL) supplemented with $10 \%$ foetal calf serum (Invitrogen Gibco $\mathrm{BRL})$ at $37^{\circ} \mathrm{C}$ in a humidified $5 \% \mathrm{CO}_{2}$ atmosphere. $\mathrm{P} 19$ cells were plated at a density of $0.5 \times 10^{5}$ 
cells per well of 24 well plates (BD Falcon). Cultures were transfected with $400 \mathrm{ng}$ of reporter vector (pGl3, pGl3-WPRE, p0.3neuroD-Luc, p0.3neuroD-Luc-WPRE, p1.3neuroD-Luc or $\mathrm{p} 1.3$ neuroD-Luc-WPRE) with or without $50 \mathrm{ng}$ of expression vector (pCS-MT-xNGNR-1a) using the calcium phosphate transfection method (Wigler et al. 1978). All transfections were achieved with $100 \mathrm{ng}$ of an internal control vector (pCH110, Amersham Pharmacia Biotech). The total amount of DNA was supplemented at $1 \mu \mathrm{g}$ per transfected well with the addition of pBluescript plasmid. During the transfection step, cells were grown at $37^{\circ} \mathrm{C}$ in a humidified $2 \% \mathrm{CO}_{2}$ atmosphere. Luciferase activity was assayed 45 hours after transfection using the luciferase assay system according to the manufacturer's protocol (Promega) and normalized with the $\beta$ Galactosidase activity (Sambrook et al. 1989). Each experiment was performed at least four times in triplicates.

\section{Embryo manipulation and microinjection of transgenes}

The use of the I-SceI meganuclease was combined with the method based on the transplantation of purified sperm nuclei (Sparrow et al. 2000). The sperm nuclei were prepared according to the protocol described by Kroll and Amaya (1996). For transgenesis, 500 ng of plasmid vectors were digested for $30 \mathrm{~min}$ at room temperature with I-SceI meganuclease (Roche Applied Science) in the appropriate buffer and then combined with 500000 sperm nuclei and incubated for 5 minutes at room temperature. The reaction was diluted in $200 \mu \mathrm{l}$ of $\mathrm{MOH}$ injection buffer $\left(\mathrm{KPO}_{4} 10 \mathrm{mM}\right.$, Kgluconate $125 \mathrm{mM}, \mathrm{NaCl} 5 \mathrm{mM}, \mathrm{MgCl}_{2} 0.5 \mathrm{mM}$, Sucrose $250 \mathrm{mM}$, Spermidine $0.25 \mathrm{mM}$ and Spermine 0.125 mM, pH 7.2; Offield et al. 2000) and back filled into glass needles. Unfertilized eggs were dejellied using 1.5\% cysteine in $0.1 \times$ MMR (Marc's Modified Ringers: Sive et al. 2000), rinsed in $0.1 \times \mathrm{MMR}$ and loaded into the square well of agarose dishes containing $6 \%$ Ficoll in $0.1 \times \mathrm{MMR}$ at $16^{\circ} \mathrm{C}$. The injection was performed using a Harvard 22 syringe pump (Harvard Instruments) with a flow rate of $0.6 \mu \mathrm{l} / \mathrm{min}$.

A few hours after injection, embryos were transferred into $0.1 \times$ MMR without Ficoll and incubated 
at $19-20^{\circ} \mathrm{C}$. Developing embryos were staged according to Nieuwkoop and Faber (1967).

\section{Genomic PCR and Southern blot hybridization}

Genomic DNA was extracted from F1 0.3neuroD-EGFP-WPRE positive or negative tadpoles. $20 \mathrm{ng}$ were used for genomic PCR reactions. A part of the transgene was amplified using the following primer set: $\quad$ xNDfor (5' TCCgCAgAAAgCACCACT $\left.3^{\prime}\right)$ and EGFPrev (5' TTgTCgggCAgCAgCACgg 3'). The PCR cycle conditions were $4 \mathrm{~min}$ at $94^{\circ} \mathrm{C}$ followed by 35 cycles of $20 \mathrm{sec}$ at $94^{\circ} \mathrm{C}, 20 \mathrm{sec}$ at $58^{\circ} \mathrm{C}, 45 \mathrm{sec}$ at $72^{\circ} \mathrm{C}$ and a final extension $7 \mathrm{~min}$ at $72^{\circ} \mathrm{C}$. PCR products were separated on a $0.8 \%$ agarose gel.

For the Southern blot analysis, $25 \mu \mathrm{g}$ of DNA was digested with either BsrG I or Bam HI, separated on a $0.8 \%$ agarose gel and transferred to a Hybond-N hybridization membrane (Amersham). Hybridization was performed with a 800 bp EGFP cDNA probe labeled with [ $\alpha 32 \mathrm{P}]-\mathrm{dCTP}$.

\section{In situ hybridisation on tissue sections}

Larvae were fixed overnight at $4 \%(\mathrm{v} / \mathrm{v})$ formaldehyde and processed for in situ hybridisation as previously described (Coumailleau and Duprez 2009). Antisense RNA probes were labelled with digoxygenin according to manufacturer's instructions (Roche Diagnostics). The probes were detected by an alkaline phosphatase-coupled antibody against digoxygenin using nitroblue tetrazolium/5-bromo-chloro-3-indolyl phosphate (NBT/BCIP) as the chromogenic substrate for alkaline phosphatase. Antisense NeuroD RNA probes were prepared as previously described (Lee et al. 1995). Antisense EGFP was produced using a TOPO/EGFP plasmid generated by subcloning a PCR product corresponding to the entire EGFP into the pCR2.1-TOPO plasmid (InVitrogen).

\section{Photomicroscopy}

Images of living transgenic animals were obtained using either a Leica MZF LIII stereomicroscope and a Leica DC300F digital camera or an inverted Leica TCS SP2 laser scanning confocal 
microscope (PIXEL platform of GIS Europia, Rennes). Confocal imaging was performed using a HC PL APO 10x (NA=0.40) objective together with a S23 (NA=0.53) condenser. Excitation was provided by the $488 \mathrm{~nm}$ laser line of Ar laser source.

\section{Image and statistical analysis}

After collection, data were analyzed with the open source software ImageJ (http://rsb.info.nih.gov/ij/). The stacks were then projected along the z-axis to give the best overview of the structure. The data obtained from transfected P19 cells were analyzed using the Student's t-test. 


\section{Results}

\section{Generation of transgenic Xenopus using a new combination of transgenesis procedures}

Our aim was to obtain transgenic animals carrying a few number of transgene copies. In this purpose, we chose a method combining the simplified version of the REMI protocol (Sparrow et al. 2000) and the Meganuclease-based method (Thermes et al. 2002; Pan et al. 2006). First attempts were performed with the construct pSce-N $\beta$ Tub-EGFP-Sce based on the promoter of a class II$\beta$ Tubuline (Neuro- $\beta$ Tubuline) that is specifically and strongly expressed in the neurons of Xenopus embryos (Moody et al. 1996). Using this construct, the EGFP fluorescence was detected in the neural tube of embryos from stage 17-18 (Fig. 1A). At tailbud stage, the spinal cord and developing brain were fluorescent (Fig. 1B). On later stage, EGFP expression was localized in the nervous system. The fluorescence was easily detected in the brain, spinal cord, retina, optic and olfactory nerves and olfactory epithelia (Fig. 1C). At stage 55, it was still detectable in the nerves of head, tail myotomes and limbs (Fig. 1D,E,F).

Of 5588 injected eggs, $142(2.5 \%)$ developed normally to stage 40 . Among these, 41 showed a strong and uniform expression in the central nervous system (CNS). 37 embryos expressed EGFP in the CNS as well as in various other tissues and 10 others expressed EGFP only outside of the CNS. This ectopic expression varied between the embryos in term of localization or intensity. One embryo uniformly expressed EGFP in only one half of his CNS reflecting a possible integration of the transgene after the first cellular division (Table 1).

Seven N $\beta$ Tub-EGFP founders, presenting a specific expression in CNS, were raised to sexual maturity and mated to wild-type animals and germline transmission rates were estimated by scoring EGFP expression (Table 2). One of these founders transmitted the transgene to $71 \%$ of its progeny, probably reflecting the existence of two integration sites. For another one, the transgene was not transmitted to the offspring suggesting either the absence of transgene integration or an integration that occurred after the differentiation of the germ cell precursors. However, five of these founders 
produced offspring with 48 to $58 \%$ of F1 animals expressing EGFP in the correct tissues. These rates are close to the Mendelian ratio for the transmission of a single locus to the offspring. This single integration event was confirmed on one of these lines by the sequence analysis of the integration site (data not shown). F2 embryos were also generated from this transgenic line. The transmission rate of the transgene was still about $50 \%$ in these animals indicating that the transgene is stably transmitted in the successive generations (Table 2).

\section{Improvment of reporter gene expression from the xneuroD promoter by the addition of WPRE element}

The use of weak promoter is often limited in transgenesis by the fact that their activity is hardly detectable. Thus we tried to improve our transgenesis method by integrating a viral element in our construct. As a weak promoter, we choose that of the Xenopus neurogenic differentiation factor neuroD gene which shows low level and restricted patterns of expression (Lee et al. 1995).

Using PCR on a Xenopus laevis genomic library, we generated a 2.4 kb DNA fragment containing a part of the xneuroD gene (accession number: EF591766). Determination of the transcription start site by RACE PCR and comparison with human (Miyachi et al. 1999) and mouse (Xu and Murphy 1998) neuroD genes showed that this fragment comprises about $1.3 \mathrm{~kb}$ of the 5 ' flanking region of this gene (data not shown).

The transcriptional activity of this neuroD promoter was assayed in transiently transfected mouse P19 cells. Luciferase reporter plasmids containing two fragments of the neuroD promoter region, termed 0.3neuroD and 1.3neuroD, were transiently transfected in mouse P19 stem cells to assess their transcriptional activities. These two fragments contained the three E-boxes involved in neuroD transcription activation (Miyachi et al. 1999; Huang et al. 2000). As shown in Fig. 2 A, the relative luciferase activities of $\mathrm{p} 0.3$ neuroD-Luc and $\mathrm{p} 1.3$ neuroD-Luc were found to be 5 to 10 -fold higher than that of pGL3. The basal activity of p0.3neuroD-Luc was 1.8 to 2-fold above p1.3neuroD-Luc activity $(\mathrm{p}<0.01)$. In the P19 cells, it is known that the basal activity of neuroD promoter is very 
low (Itoh et al. 1997; Kim et al. 2004) but can be strongly induced by another bHLH factor, Neurogenin (Ngn) (Kim et al. 2004). Thus, in order to determine the ability of Ngn-1 to enhance the activity of the neuroD promoter fragments, P19 cells were co-transfected with a Xenopus Neurogenin-related-1 expression vector, pCS2-X-Ngnr-1a. This resulted in a strong increase of both 0.3neuroD and 1.3neuroD activity (9 and 11.6-fold respectively, p<0.001) (Fig. 2A).

To increase reporter gene expression both in vitro and in vivo, WPRE was inserted in our plasmid constructs downstream of the open reading frame of the reporter gene. The efficiency of WPRE was then assessed after transient transfection of two constructs, p0.3neuroD-Luc-WPRE and p1.3neuroD-Luc-WPRE, in P19 cells. Adding WPRE induced a 1.75 and 1.9-fold $(\mathrm{n}=18, \mathrm{p}<0.002)$ increase of the luciferase activity when used with the 0.3 neuroD or 1.3 neuroD promoter fragments respectively, when compared with the same constructs lacking WPRE (Fig. 2B).

\section{Effects of WPRE on transgene expression in vivo}

In order to obtain transgenic embryos, 0.3 neuroD and 1.3 neuroD promoter fragments were bound to EGFP, with or without WPRE, and flanked by an I-SceI recognition site at both extremities.

At stage $40,18 \%$ of the animals $(n=34)$ expressed EGFP in the eye, brain and spinal cord when placed under the control of 0.3 neuroD promoter. For $9 \%$ of these embryos, the EGFP detection in the future nervous system was already possible at stages 18/20. The addition of WPRE to the same construct gave $63 \%$ of EGFP-expressing animals at stage $40(n=51)$, and fluorescence detection began earlier at stage 15 for $19 \%$ of embryos. At stages 18/20, $35 \%$ of neurula embryos were labelled in the future nervous system (Table 3). With 1.3neuroD promoter fragment, no expression in the nervous system was obtained. However, the addition of WPRE allowed EGFP detection in the CNS from stage 33 with p1.3neuroD-EGFP-WPRE construct. At stage 40, EGFP expression was localised in the brain and eyes for two of the eight surviving animals (Table 3). No expression was observed in the spinal cord contrary to observations with 0.3 neuroD promoter fragment.

The preservation of tissue and cellular specificity was checked for the 0.3neuroD promoter 
construct carrying the WPRE using both confocal microscopy on living embryos and in situ hybridisation on fixed tissues. At stage 40, confocal microscopy imaging performed on living embryos showed EGFP fluorescence in the five encephalic vesicles (telencephalon, diencephalon, mesencephalon, metencephalon and myelencephalon as well as in the retina (Fig. 3A) and the spinal cord (not shown). At stage 48, the fluorescence level remained elevated in the pallia, the cerebellum and the rhombencephalon (Fig. 3B). In order to precisely check the activity of the 0.3neuroD promoter in transgenic embryos, we performed in situ hybridisation to detect both EGFP and endogenous NeuroD transcripts. We showed that EGFP expression was clearly restricted to the brain area that expressed the endogenous neuroD gene since both signals are superimposed in the cerebellum (Fig.4A,B) and rhombencephalon (Fig. 4C,D).

NeuroD, also referred as BETA2, is expressed in the pancreas (Naya et al. 1995; Kelly and Melton 2000). Spectral analysis in confocal microscopy showed that EGFP was expressed in the pancreas of transgenic animals (data not shown). However, this fluorescence was quite difficult to observe in classical fluorescent microscopy because of the high auto-fluorescence of this tissue.

Some embryos expressing EGFP under the control of 0.3 neuroD promoter from a construct containing WPRE element were raised to sexual maturity and used to estimate the transmission rate to the F1 offspring. As previously obtained with pSce-N $\beta$ Tub-EGFP-Sce, a majority of the founders (5 out of 6) transmitted the transgene to about $50 \%$ of their progeny (Table 4). Transgene integration was analyzed in one of these lines using genomic PCR and Southern blot. Both methods showed that EGFP fragments can be detected only in EGFP-positive animals indicating that the absence of expression in EGFP-negative animals is not due to transgene silencing (Fig. 5 A,C). Moreover, the patterns observed in the Southern blot experiment are consistent with the hypothesis of a single integration of the transgene in the host genome. The presence of a weak band of about 2 $\mathrm{kb}$ indicated that the transgene might be inserted as a tandem repeat (Fig $\mathbf{5 B}, \mathbf{C})$. Transmission rate to the F2 generation was also assessed for one of these transgenic lines and was found to be stable between the different generations (Table 4). 


\section{Discussion}

In this study, we showed that the combination of two previously described protocols, namely the REMI (Kroll and Amaya 1996) and I-SceI meganuclease (Thermes et al. 2002) methods, allowed the obtention of a high rate of fully transgenic animals in the F0 generation with a limited number of transgene integration events. This was assessed with different constructs based on the use of promoters of two genes, $\mathrm{N} \beta$ Tubuline and NeuroD, that have different transcriptional activities. N $\beta$ Tubuline is a class-II $\beta$ tubulin that is specifically and strongly expressed in differentiated neurons (Moody et al. 1996) whereas NeuroD is a transcription factor that belongs to the bHLH superfamily and promotes the differentiation of neuronal precursor cells in neurons (Lee et al. 1995). Morevover, this latter gene presents low level and restricted pattern of expression.

The limitation of integration events was shown by the transmission rates close to $50 \%$ obtained from a majority of F0 founders and genomic DNA analysis, both indicating an integration in a single site of the host genome. In this case, all the siblings obtained from a single founder exhibited the same pattern of expression and similar level of fluorescence. This is in contrast with the results published by Marsh-Armstrong et al. (1999) reporting that most of the founders produced by the REMI method presented 2 to more than 4 integration events which resulted in siblings presenting various fluorescence intensities. F2 embryos expressing EGFP were also produced from some F1 adults mated with wild type animals showing that the transgene is stably integrated in germline cells. Moreover, the transgene transmission rate is the same between F1 and F2 generations as between F0 and F1.

Combining the protocols was found to be far more efficient than using the I-SceI meganuclease alone in term of transgene transmission between F0 and F1. Indeed, with I-SceI alone, the transmission rate rarely reaches $50 \%$ whatever the animal species indicating that, in this case, the integration into the host genome occurs mainly after the first cellular division (Thermes et al. 2002;

Deschet et al. 2003; Grabher et al. 2004; Ogino et al. 2006; Pan et al. 2006; Sobkow et al. 2006). It 
is interesting to note that in our hands this method gave almost the same results (one transgenic line with a transmission rate close to $50 \%$ on 6 tested, unpublished data).

The mechanisms involved in the limitation of integration events when I-SceI meganuclease is used together with sperm nuclei remain largely unknown. However, it is clear that the incubation of the transgene with sperm nuclei promotes its rapid integration in the genome reducing the number of embryos presenting a mosaic expression of this transgene. Although this cannot be totally ruled out, it is very unlikely that I-SceI facilitates transgene integration by generating double strand breaks (DSB) in Xenopus genomic DNA since it has a 18-bp long recognition site and therefore a low probability of cutting in the host genome. Another possibility is that the integration happens after the introduction of sperm nuclei into the oocyte. In this case, sperm nuclei could only be vectors that carry the transgene into the cell and the integration could occur at the time of pronuclei fusion. As previously demonstrated, exogenous DNA incubated with sperm cells or purified nuclei is rapidly internalized (Francolini et al. 1993) and mature sperm cells can even be used as vectors to introduce DNA into eggs and generate transgenic animals (Lavitrano et al. 1989). Whatever the precise mechanism involved in the integration, I-SceI could intervene in DSB repair as it apparently proceeds in yeast where it promotes intron homing (for review, see Dujon 1989).

Although it probably needs to be confirmed in various promoter contexts, we showed in this paper that WPRE could be useful to enhance transgene expression in Xenopus without affecting its tissuespecificity. WPRE is a post-transcriptional regulatory element (Donello et al. 1998) that does not interfere with the promoter activity and its efficiency was previously demonstrated in different tissues using adenovirus vectors (Xu et al. 2003). It probably functions by modifying the RNA polyadenylation, export and/or translation (Zufferey et al. 1999; Mastroyiannopoulos et al. 2005), so that the transgene product accumulates more quickly and is detectable earlier on. The RNA export function of WPRE involves in a cellular factor CRM-1, an export receptor for leucine-rich nuclear export signals (Fornerod et al. 1997; Popa et al. 2002). A deficiency in this factor may explain the negative effects of WPRE observed in some cases (Werner et al. 2004; Klein et al. 2006). In 
Xenopus, the CRM-1 factor is present during the early stage of embryogenesis and becomes functional before the neurulation (Callanan et al. 2000).

The efficiency of the association between the xneuroD promoter and WPRE was first assessed by transfection studies in the pluripotent P19 embryonal carcinoma cells that can differentiate in neuronal cells upon a retinoic acid treatment. The difference in the activities observed with the two promoter fragments used can be explained by the presence of a potential binding site for the transcriptional repressor IA-1 in the 1.3neuroD fragment (Breslin et al. 2002). The addition of WPRE significantly increased the reporter gene expression with both promoter fragments. Our results are close to the 1.5 -fold induction in RNA or protein levels obtain in a plasmid vector context when this vector is stably integrated in the host cells (Johansen et al. 2003). Using adenoviral vector, Glover et al. (2002) also reported a similar elevation with the SYN1 promoter which drives a neuron-specific expression. Other studies reported higher elevations. However, these works were based on the use of retroviral or lentiviral vectors and strong promoters such as CMV (cytomegalovirus) or MMTV (mouse mammary tumour virus) promoters (Zufferey et al. 1999; Klein et al. 2006).

The ability of WPRE to promote gene expression was then evaluated in vivo in transgenic Xenopus embryos. Addition of this element in the plasmid vector used for transgenesis increased the reporter gene expression driven by the 0.3neuroD promoter and allowed an earlier detection of EGFP in more embryos $(63 \%)$ without modifying the localization in the nervous system. This improvement in the detection of transgene expression was notably observed with the 1.3neuroD promoter fragment. The enhancement of reporter expression, due to the improvement of the transgenic technique and the addition of the WPRE element, permitted an early detection (stage 15) of EGFP controlled by Xenopus neuroD promoter, which occurs slightly later than the appearance of neuroD mRNA at stage 13.5/14 (Lee et al. 1995; Ma et al. 1996). Transgene expression with p0.3neuroDEGFP-WPRE was found to be specifically localized in the developing nervous system, in structures in which neuroD mRNA was detected (Lee et al. 1995; Ma et al. 1996; Huang et al. 2000; Schlosser 
and Northcutt 2000; Schlosser et al. 2002). This concordance was maintained at later stage. Indeed, at stage 48, confocal microscopy imaging as well as in situ hybridisation studies allowed the detection of EGFP in limited areas corresponding to neuroD-expressing brain areas during neurogenesis in Xenopus (Wullimann et al. 2005).

Thus, in this study, we describe a transgenesis method that allows the production of fully transgenic F0 animals with a limited number of insertion events. Moreover, we show that regulatory elements such as WRPE can be successfully used to improve transgene expression in Xenopus making possible the use of a promoter with low activity to label a group of cells or a particular tissue. 


\section{Acknowledgements}

This work was supported by funds from the Région Bretagne, the Ministère de l'Education Nationale et de l'Enseignement Supérieur et de la Recherche. We thank C. Cajat and N. Even for technical assistance, S. Lemarchand for taking care of the Xenopus facilities and P. Benquet for critical reading of the manuscript. 


\section{References}

Allen BG, Weeks DL (2005) Transgenic Xenopus laevis embryos can be generated using phiC31 integrase. Nat Methods. 2:975-979.

Amaya E, Musci TJ, Kirschner MW (1991) Expression of a dominant negative mutant of the FGF receptor disrupts mesoderm formation in Xenopus embryos. Cell 66:257-270.

Breslin MB, Zhu M, Notkins AL, Lan MS (2002) Neuroendocrine differentiation factor, IA-1, is a transcriptional repressor and contains a specific DNA-binding domain: identification of consensus IA-1 binding sequence. Nucleic Acids Res 30:1038-1045.

Callanan M, Kudo N, Gout S, Brocard MP, Yoshida M, Dimitrov S, Khochbin S (2000) Developmentally regulated activity of CRM1/XPO1 during early Xenopus embryogenesis. J Cell Science 113:451-459

Colleaux L, D'Auriol L, Galibert F, Dujon B (1988) Recognition and cleavage site of the intronencoded omega transposase. Proc Natl Acad Sci USA 85:6022-6026.

Coumailleau P, Duprez D (2009) Sim1 and Sim2 expression during chick and mouse limb development. Int J Dev Biol 53:149-157.

Deschet K, Nakatani Y, Smith WC (2003) Generation of Ci-Brachyury-GFP stable transgenic lines in the ascidian Ciona savignyi. Genesis 35:248-259.

Donello JE, Loeb JE, Hope TJ (1998) Woodchuck hepatitis virus contains a tripartite posttranscriptional regulatory element. J Virol 72:5085-5092.

Dujon B (1989) Group I intron as mobile genetic elements: facts and mechanistic speculations--a review. Gene 82:91-114.

Fornerod M, Ohno M, Yoshida M, Mattaj IW (1997) CRM1 is an export receptor for leucine-rich nuclear export signals. Cell 90:1051-1060.

Francolini M, Lavitrano M, Lamia CL, French D, Frati L, Cotelli F, Spadafora C (1993) Evidence for nuclear internalization of exogenous DNA into mammalian sperm cells. Mol Reprod Dev 34:133-139.

Glover CP, Bienemann AS, Heywood DJ, Cosgrave AS, Uney JB (2002) Adenoviral-mediated, high-level, cell-specific transgene expression: a SYN1-WPRE cassette mediates increased transgene expression with no loss of neuron specificity. Mol Ther 5:509-16.

Grabher C, Joly JS, Wittbrodt J (2004) Highly efficient zebrafish transgenesis mediated by the meganuclease I-SceI. Methods Cell Biol 77:381-401. 
Hamlet MR, Yergeau DA, Kuliyev E, Takeda M, Taira M, Kawakami K, Mead PE (2006) Tol2 transposon-mediated transgenesis in Xenopus tropicalis. Genesis 44:438-445.

Heasman J, Kofron M, Wylie C (2000) Beta-catenin signaling activity dissected in the early Xenopus embryo: a novel antisense approach. Dev Biol 222:124-134.

Heasman J (2006) Patterning the early Xenopus embryo. Development 133:1205-1217.

Huang HP, Liu M, El-Hodiri HM, Chu K, Jamrich M, Tsai MJ (2000) Regulation of the pancreatic islet-specific gene BETA2 (neuroD) by neurogenin 3. Mol Cell Biol 20:3292-307.

Itoh F, Nakane T, Chiba S (1997) Gene expression of MASH-1, MATH-1, neuroD and NSCL-2, basic helix-loop-helix proteins, during neural differentiation in P19 embryonal carcinoma cells. Tohoku J Exp Med 182:327-36.

Johansen J, Tornøe J, Møller A, Johansen TE (2003) Increased in vitro and in vivo transgene expression levels mediated through cis-acting elements. J Gene Med 5:1080-1089.

Kelly OG, Melton DA (2000) Development of the pancreas in Xenopus laevis. Dev Dyn 218:615627.

Kim S, Yoon YS, Kim JW, Jung M, Kim SU, Lee YD, Suh-Kim H (2004) Neurogenin1 is sufficient to induce neuronal differentiation of embryonal carcinoma P19 cells in the absence of retinoic acid. Cell Mol Neurobiol 24:343-356.

Klein R, Ruttkowski B, Knap E, Salmons B, Günburg WH, hohenadl C (2006) WPRE-mediated enhancement of gene expression is promoter and cell lines specific. Gene 372:153-161.

Kroll KL, Amaya E (1996) Transgenic Xenopus embryos from sperm nuclear transplantations reveal FGF signaling requirements during gastrulation. Development 122:3173-3183.

Kuspa A, Loomis WF (1992) Tagging developmental genes in Dictyostelium by restriction enzymemediated integration of plasmid DNA. Proc Natl Acad Sci USA 89:8803-8807.

Johansen J, Tornoe J, Moller A, Johansen TE (2003) Increased in vitro and in vivo transgene expression levels mediated through cis-acting elements. J Gene Med 5:1080-1089.

Lavitrano M, Camaioni A, Fazio VM, Dolci S, Farace MG, Spadafora C (1989) Sperm cells as vectors for introducing foreign DNA into eggs: genetic transformation of mice. Cell 57:717-723.

Lee JE, Hollenberg SM, Snider L, Turner DL, Lipnick N, Weintraub H (1995) Conversion of Xenopus ectoderm into neurons by NeuroD, a basic helix-loop-helix protein. Science 268:836-844.

Ma Q, Kintner C, Anderson DJ (1996) Identification of neurogenin, a vertebrate neuronal 
determination gene. Cell 87:43-52.

Marsh-Armstrong N, Huang H, Berry DL, Brown DD (1999) Germ-line transmission of transgenes in Xenopus laevis. Proc Natl Acad Sci USA 96:14389-14393.

Mastroyiannopoulos NP, Feldman ML, Uney JB, Mahadevan MS, Phylactou LA (2005) Woodchuck post-transcriptional element induces nuclear export of myotonic dystrophy 3' untranslated region transcripts. EMBO Rep 6:458-463.

Moody SA, Miller V, Spanos A, Frankfurter A (1996) Developmental expression of a neuronspecific $\beta$-Tubulin in Frog (Xenopus laevis): a marker for growing axons during the embryonic period. J Comp Neurol 364:219-230.

Miyachi T, Maruyama H, Kitamura T, Nakamura S, Kawakami H (1999) Structure and regulation of the human NeuroD (BETA2/BHF1) gene. Brain Res Mol Brain Res 69:223-231.

Naya FJ, Stellrecht CM, Tsai MJ (1995) Tissue-specific regulation of the insulin gene by a novel basic helix-loop-helix transcription factor. Genes Dev 9:1009-1019.

Nieuwkoop PD, Faber P (1967) Normal Table of Xenopus laevis (Daudin). North-Holland Pub. Co., Amsterdam.

Offield MF, Hirsch N, Grainger RM (2000) The development of Xenopus tropicalis transgenic lines and their use in studying lens developmental timing in living embryos. Development 127:17891797.

Ogino H, McConnell WB, Grainger RM (2006) Highly efficient transgenesis in Xenopus tropicalis using I-SceI meganuclease. Mech Dev 123:103-13.

Pan FC, Chen Y, Loeber J, Henningfeld K, Pieler T (2006) I-SceI meganuclease-mediated transgenesis in Xenopus. Dev Dyn 235:247-252.

Popa I, Harris ME, Donello JE, hope TJ (2002) CRM1-dependent function of a cis-acting RNA export element. Mol Cell Biol 22:2057-2067.

Ryffel GU, Lingott A (2000) Distinct promoter elements mediate endodermal and mesodermal expression of the HNF1alpha promoter in transgenic Xenopus. Mech Dev 90:65-75.

Sambrook J, Fritsch EF, Maniatis T (1989) Molecular Cloning: A Laboratory Manuel. Cold Sping Harbor Laboratory Press, New York.

Schlosser G, Northcutt RG (2000) Development of neurogenic placodes in Xenopus laevis. J Comp Neurol 418:121-146.

Schlosser G, Koyano-Nakagawa N, Kintner C (2002) Thyroid hormone promotes neurogenesis in 
the Xenopus spinal cord. Dev Dyn 225:485-498.

Sinzelle L, Vallin J, Coen L, Chesneau A, Du Pasquier D, Pollet N, Demeneix B, Mazabraud A (2006) Generation of trangenic Xenopus laevis using the Sleeping Beauty transposon system. Transgenic Res 15:751-760.

Sive HL, Grainger RM, Harland RM (2000) Early development of Xenopus laevis; A laboratory manual. Cold Sping Harbor Laboratory Press, New York.

Sobkow L, Epperlein HH, Herklotz S, Straube WL, Tanaka EM (2006) A germline GFP transgenic axolotl and its use to track cell fate: dual origin of the fin mesenchyme during development and the fate of blood cells during regeneration. Dev Biol 290:386-397.

Sparrow DB, Latinkic B, Mohun TJ (2000) A simplified method of generating transgenic Xenopus. Nucleic Acids Res 28:E12.

Stern CD (2005) Neural induction: old problem, new findings, yet more questions.

Development 2005 132:2007-2021.

Thermes V, Grahber C, Ristoratore F, Bourrat F, Choulika A, Wittbrodt J, Joly JS (2002) I-SceI meganuclease mediates highly efficient transgenesis in fish. Mech Dev 118:91-98.

Werner M, Kraunus J, Baum C, Brocker T (2004) B-cell-specific transgene expression using a selfinactivating retroviral vector with human CD19 promoter and viral post-transcriptional regulatory element. Gene Ther 11:992-1000.

Wigler M, Pellicer A, Silverstein S, Axel R (1978) Biochemical transfer of single-copy eucaryotic genes using total cellular DNA as donor. Cell 14:725-731.

Wullimann MF, Rink E, Vernier P, Schlosser G (2005) Secondary neurogenesis in the brain of the African clawed frog, Xenopus laevis, as revealed by PCNA, Delta-1, Neurogenin-related-1, and NeuroD expression. J Comp Neurol 489:387-402.

$\mathrm{Xu}$ W, Murphy LJ (1998) Isolation and characterization of the mouse beta 2/neuroD gene promoter. Biochem Biophys Res Commun 247:814-818.

Xu ZL, Mizuguchi H, Mayumi T, Hayakawa T (2003) Woodchuck hepatitis virus posttranscriptional regulation element enhances transgene expression from adenovirus vectors. Biochim Biophys Acta 1621:266-271.

Zufferey R, Donello JE, Trono D, Hope T (1999) Woodchuck hepatitis virus posttranscriptional regulatory element enhances expression of transgenes delivered by retroviral vectors. J Virol 73:2886-2892. 


\section{Figure legends}

Fig. 1 In vivo Expression of the N $\beta$ Tub-EGFP transgene co-injected with I-SceI meganuclease and sperm nuclei into $X$. laevis oocytes

Fluorescence can be detected in the neural tube at stage 18 (A), the brain and spinal cord at stage 34 (B) or $46(\mathrm{C})$, the brain, retina and cranial nerves such as optic or olfactory nerves at stage 55 (D). The innervation of the tail myotomes $(\mathrm{E})$ and hind limbs $(\mathrm{F})$ is also easily detectable (NT: neural tube; B: brain; SC: spinal cord; Olf: olfactory nerve; Opt: optic nerve). Scale bar: (A) $500 \mu \mathrm{m}$; (B,C) $1 \mathrm{~mm}$; (D,E,F) $2 \mathrm{~mm}$.

\section{Fig. 2 Activation of XneuroD promoter fragments in P19 cells}

(A) P19 cells were transfected with pGL3, p0.3neuroD-Luc or p1.3neuroD-Luc constructs. NeuroD promoter fragments activities were assayed with pCS2-X-Ngnr-1a (+NGN) cotransfection. Activities were normalized to that of pGL3. (B) Effect of the WPRE element addition in the reporter constructs was assessed. Data represent relative luciferase activity obtained 45 hours after transfection and normalized to $\beta$-Galactosidase activity, expressed from a cotransfected control plasmid. Each activity is the mean \pm SEM of at least four independent experiments with triplicate transfections (A and $\mathrm{B})$.

Fig. 3 Confocal microscopy images of EGFP expression in live transgenic F1 embryos obtained with p0.3neuroD-EGFP-WPRE construct

(A) EGFP fluorescence was found in the retina and the five embryonic brain vesicles of stage 40-41 (Tel: Telencephalon, Di: Diencephalon, Mes: Mesencephalon, Met: Metencephalon, Myel: Myelencephalon, Ret: Retina). (B) In vivo spatial expression of EGFP fluorescence in the whole brain of a stage 48 embryo. (Pa: pallium, OT: Optic Tectum, C: Cerebellum, Rho: Rhombencephale); Scale bar: $100 \mu \mathrm{m}$

Fig. 4 In situ hybridisation analysis of $x$ NeuroD and EGFP expression in transgenic 0.3NeuroD-EGFP-WPRE larva (stage 48)

Consecutive transverse sections at the level of cerebellum (A,B) and rhombencephalon (C,D) were hybridized with the $\mathrm{xNeuroD}(\mathrm{A}, \mathrm{C})$ and $\operatorname{EGFP}(\mathrm{B}, \mathrm{D})$ probes. Dorsal is to the top. Arrow indicates the position of a ganglion of the cranial nerve IX. Scale bar: $100 \mu \mathrm{m}$ 
Fig. 5 PCR and Southern blot analysis on genomic DNA from 0.3neuroD-EGFP-WPRE animals

(A) Genomic PCR of F1 siblings from a 0.3neuroD-EGFP-WPRE founder. Lanes labeled (-) or (+) represent genomic DNA from individual EGFP-negative or EGFP-positive tadpoles respectively. $\mathrm{Wt}$ is a control performed on wild-type genomic DNA. M: DNA ladder (B) Schematic representation of the transgene with the relative position of the probe and restriction sites. Below, products expected after transgene integration according to the different possibilities of concatemerization. (C) Southern blot analysis of F1 progeny. DNA from EGFP-positive tadpoles was digested by either BsrG I (lane1) or Bam HI (lane 2). DNA from EGFP-negative tadpoles was digested by $B s r G$ I (lane3). 
Fig. 1

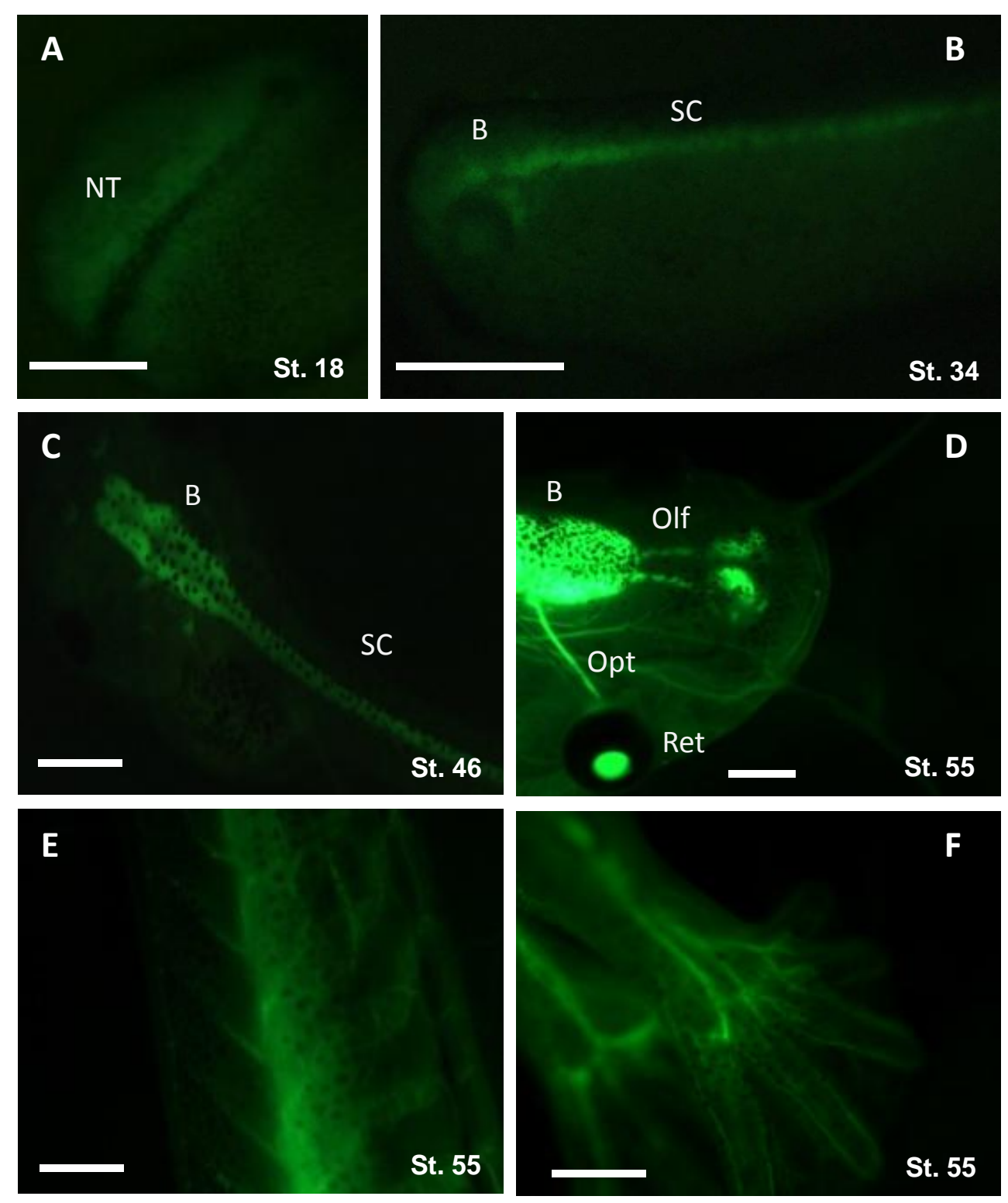


Fig. 2

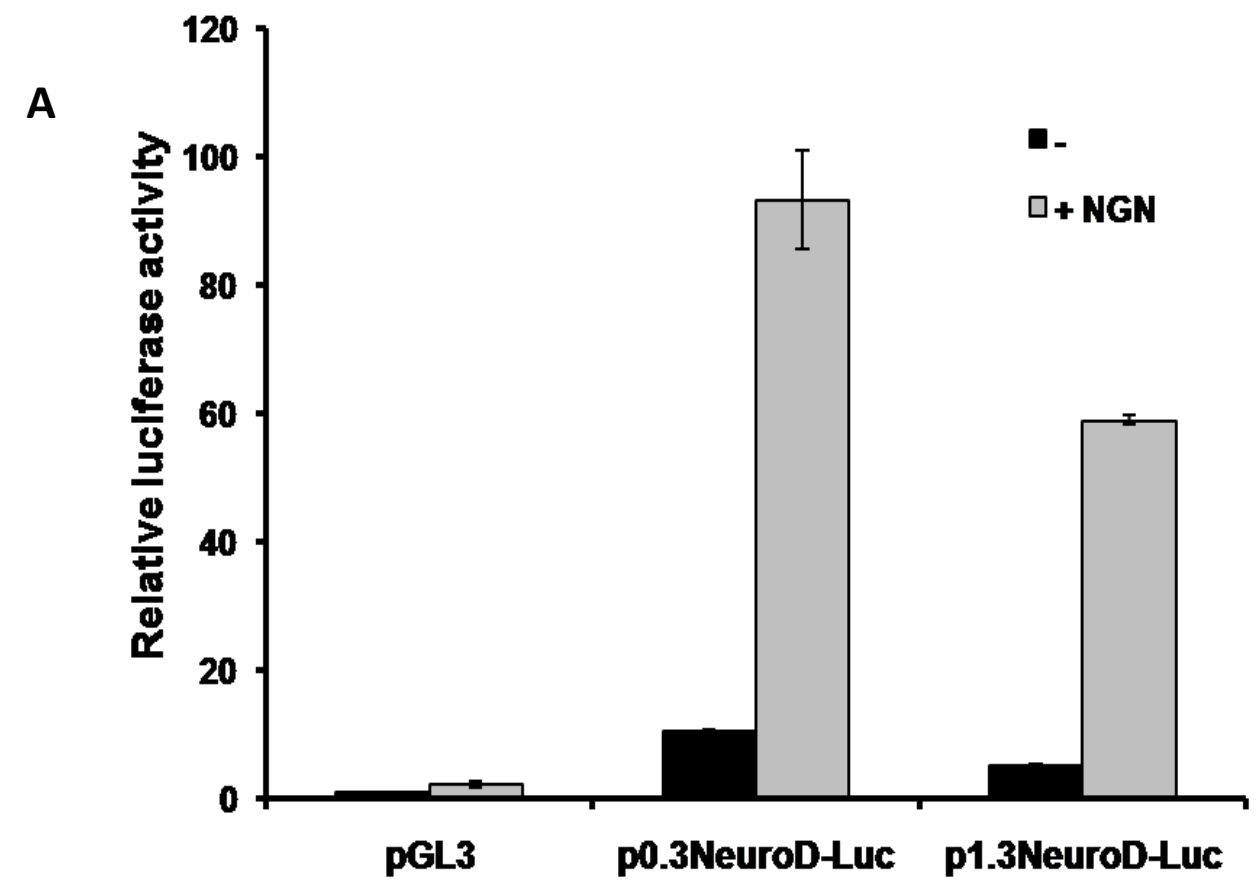

B

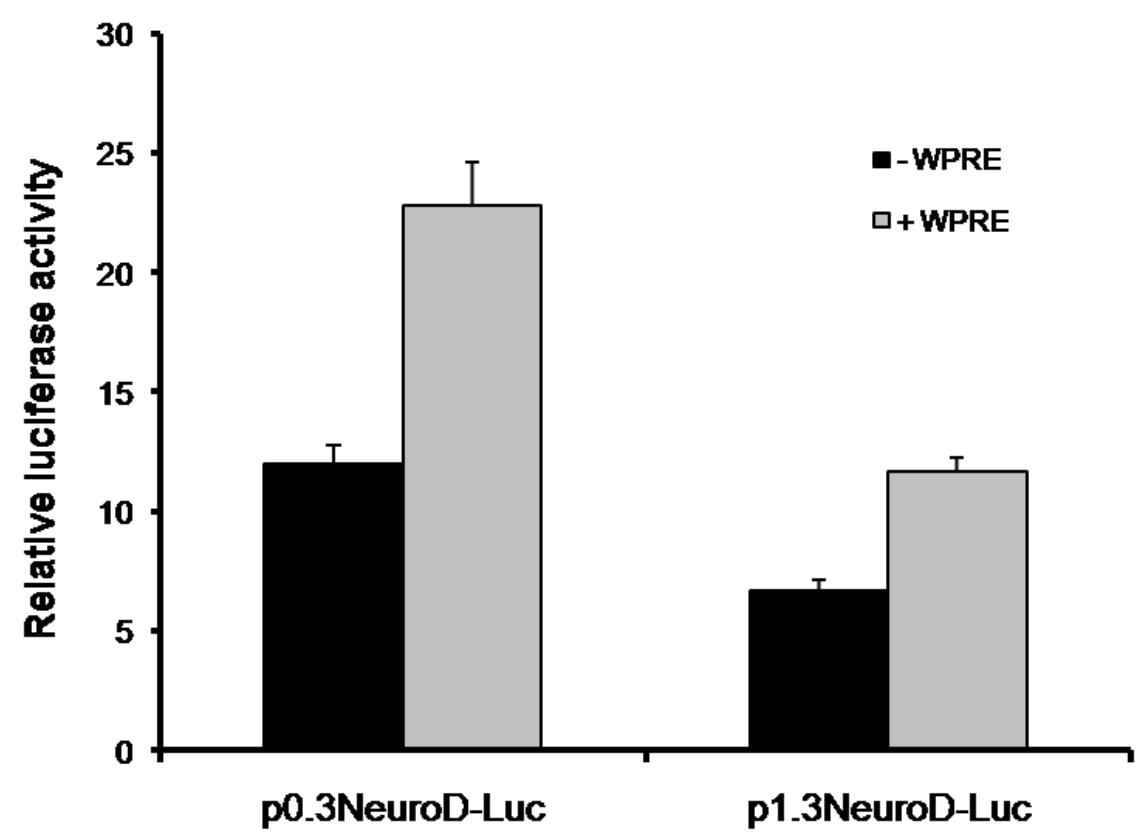


Fig. 3

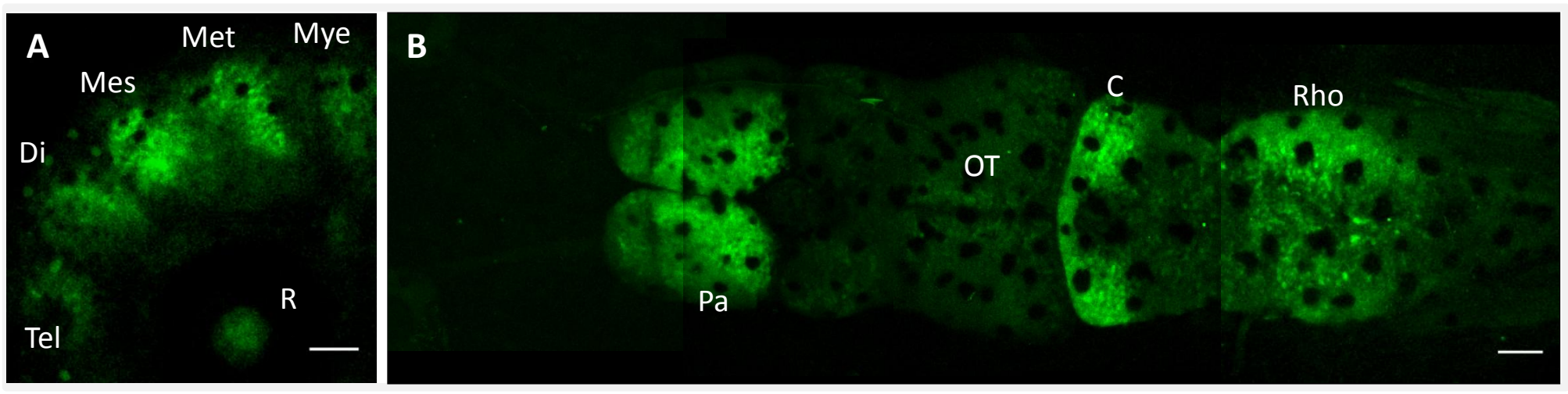


Fig. 4
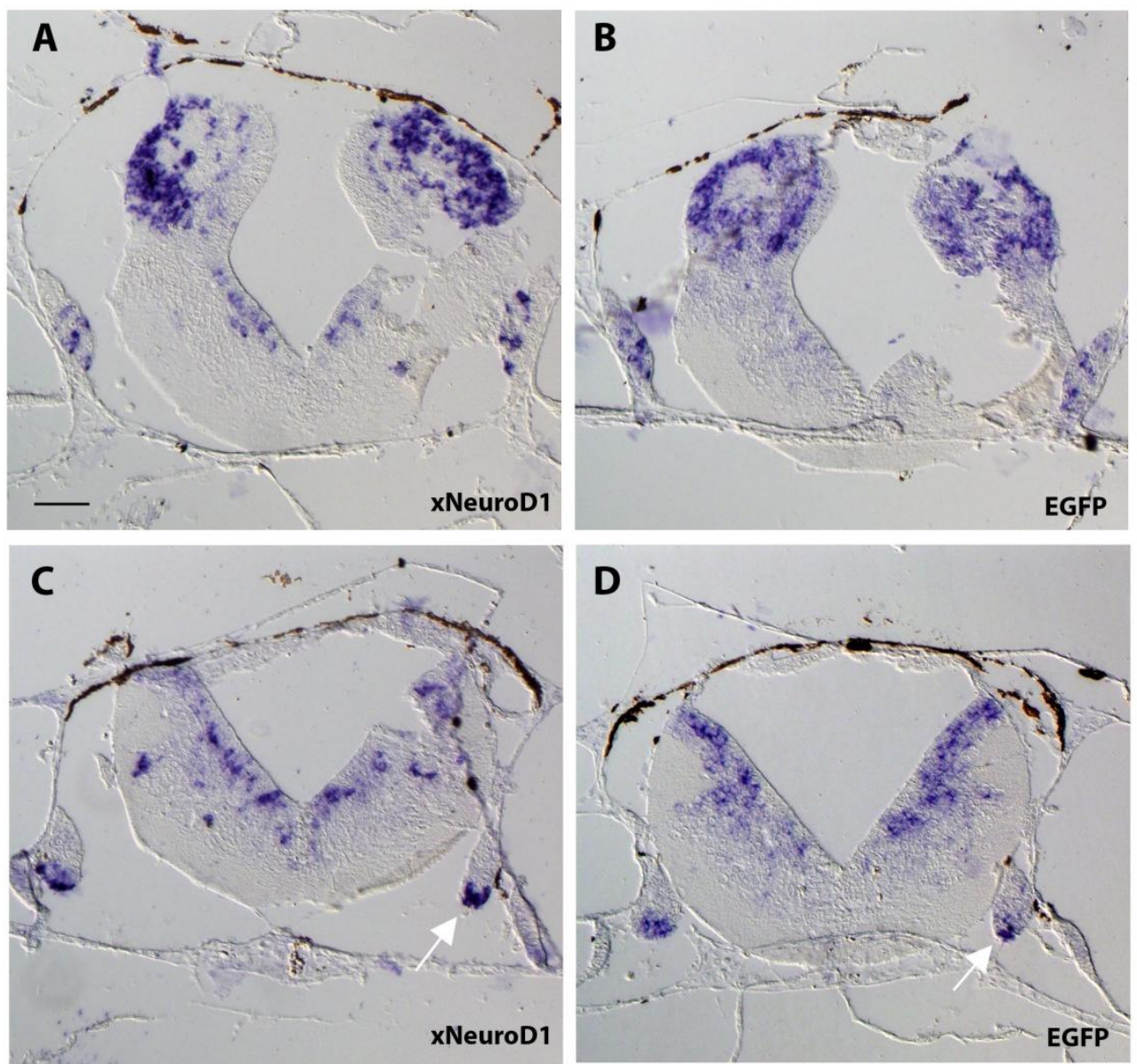
Fig.5

A

0.3neuroD-EGFP-WPRE

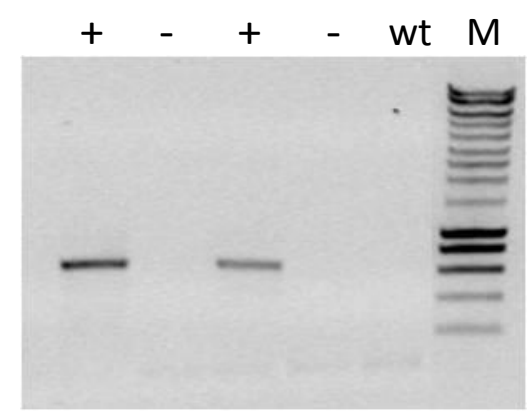

B

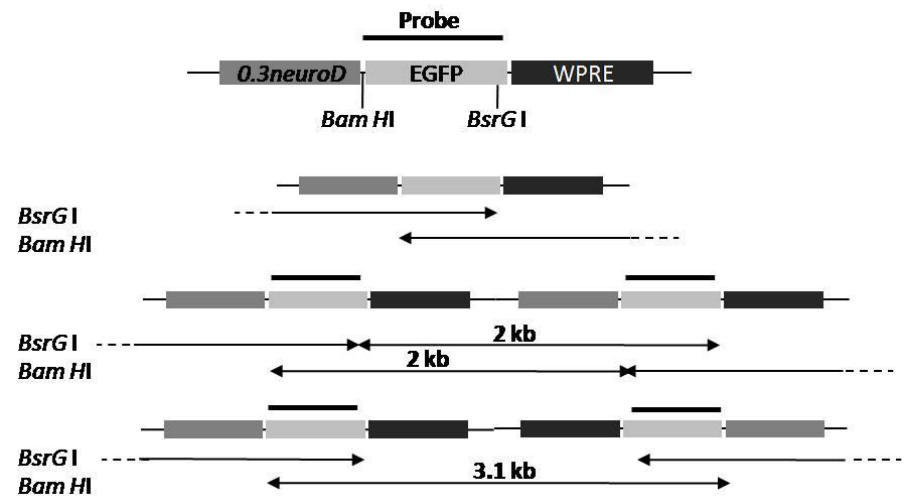

C

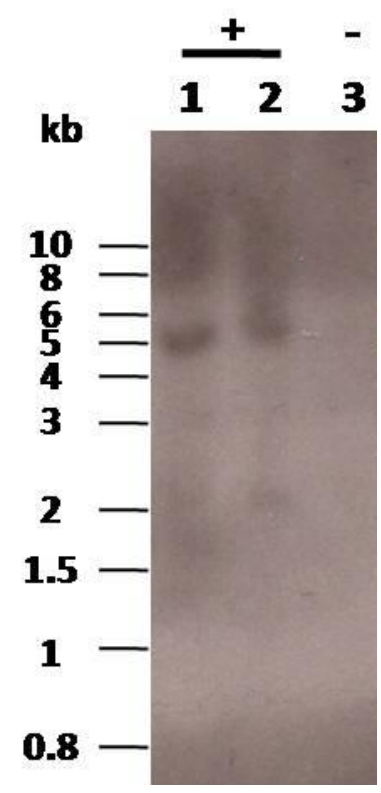


Table 1 : Transgenesis efficiency for the N $\beta$ Tub-EGFP construct

\begin{tabular}{|c|c|c|c|c|c|c|c|}
\hline \multirow[b]{2}{*}{ Plasmid } & \multirow[b]{2}{*}{ Injected eggs } & \multirow[b]{2}{*}{$\begin{array}{c}\text { surviving embryos } \\
\text { at stage } 40\end{array}$} & \multicolumn{5}{|c|}{$\%$ of EGFP expressing embryos at stage 40} \\
\hline & & & SNC specific & Hemi body & $\begin{array}{c}\text { SNC and } \\
\text { other tissues }\end{array}$ & Ectopic & None \\
\hline $\begin{array}{c}\text { pSce-NbTub-EGFP- } \\
\text { Sce }\end{array}$ & 5588 & 142 & 29 & 0.7 & 26 & 7 & 37 \\
\hline
\end{tabular}


Table 2 : Germline transmission of the N $\beta$ Tub -EGFP transgene

\begin{tabular}{|c|c|c|c|c|}
\hline Fo founder & $\begin{array}{l}\text { EGFP+ embryos / } \\
\text { total F1 embryos }\end{array}$ & $\begin{array}{l}\text { Transmission } \\
\text { rate (\%) }\end{array}$ & $\begin{array}{l}\text { EGFP+ embryos / } \\
\text { total F2 embryos }\end{array}$ & $\begin{array}{l}\text { Transmission rate } \\
\text { (\%) }\end{array}$ \\
\hline pN $\beta$ Tub-EGFP \#1 & $0 / 59$ & 0 & & \\
\hline pN $\beta$ Tub-EGFP \#2 & $585 / 1167$ & 48 & $255 / 534$ & 47.53 \\
\hline pN $\beta$ Tub-EGFP \#3 & $270 / 529$ & 51 & & \\
\hline pN $\beta$ Tub-EGFP \#4 & $213 / 365$ & 58 & & \\
\hline pN $\beta$ Tub-EGFP \#5 & $52 / 98$ & 53 & & \\
\hline pN $\beta$ Tub-EGFP \#6 & $403 / 790$ & 51 & & \\
\hline pN $\beta$ Tub-EGFP \#7 & $418 / 589$ & 71 & & \\
\hline
\end{tabular}


Table 3 : EGFP fluorescence driven by xneuroD promoter fragments at different stages of development

\begin{tabular}{|c|c|c|c|c|c|c|}
\hline \multirow[b]{2}{*}{ Plasmids } & \multirow[b]{2}{*}{ Injected eggs } & \multicolumn{4}{|c|}{$\%$ of embryos expressing EGFP in the developing nervous system } & \multirow{2}{*}{$\begin{array}{c}\% \text { of surviving } \\
\text { embryos at stage } 40\end{array}$} \\
\hline & & stage 15 & stages $18 / 20$ & stage 33 & stage 40 & \\
\hline 0.3 NeuroD-EGFP & 2250 & $0(0 / 69)$ & $9(6 / 69)$ & $21(11 / 52)$ & $18(6 / 34)$ & 1.5 \\
\hline 0.3NeuroD-EGFP-WPRE & 1357 & $19(16 / 83)$ & $35(29 / 83)$ & $48(30 / 62)$ & $63(32 / 51)$ & 3.75 \\
\hline 1.3NeuroD-EGFP & 1181 & $0(0 / 18)$ & $0(0 / 18)$ & $0(0 / 16)$ & $0(0 / 2)$ & 0.17 \\
\hline 1.3NeuroD-EGFP-WPRE & 1647 & $0(0 / 39)$ & $0(0 / 39)$ & $7(2 / 27)$ & $25(2 / 8)$ & 0.5 \\
\hline
\end{tabular}


Table 4 : Germline transmission of the 0.3neuroD-EGFP-WPRE transgene

\begin{tabular}{lcccc}
\hline Fo founder & $\begin{array}{c}\text { EGFP+ embryos / } \\
\text { total F1 embryos }\end{array}$ & $\begin{array}{c}\text { Transmission } \\
\text { rate (\%) }\end{array}$ & $\begin{array}{c}\text { EGFP+ embryos / } \\
\text { total F2 embryos }\end{array}$ & $\begin{array}{c}\text { Transmission } \\
\text { rate (\%) }\end{array}$ \\
\hline p0.3NeuroD-EGFP-WPRE \#1 & $119 / 310$ & 46 & \\
p0.3NeuroD-EGFP-WPRE \#2 & $115 / 125$ & 92 & 51 \\
p0.3NeuroD-EGFP-WPRE \#3 & $604 / 1137$ & 53 & \\
p0.3NeuroD-EGFP-WPRE \#4 & $549 / 1173$ & 47 & \\
p0.3NeuroD-EGFP-WPRE \#5 & $21 / 49$ & 43 & \\
p0.3NeuroD-EGFP-WPRE \#6 & $42 / 104$ & 40 & \\
\hline
\end{tabular}

